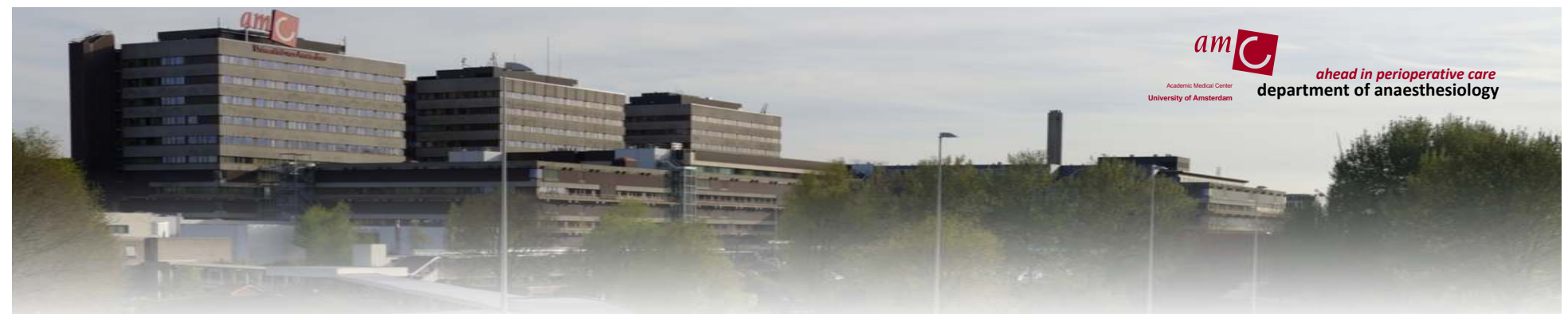

\title{
Current perioperative management of patients with diabetes mellitus in Dutch hospitals.
}

\author{
Hulst $\mathrm{AH}^{1}$, Hermanides $\mathrm{J}^{1}$, DeVries $\mathrm{JH}^{2}$, Preckel $\mathrm{B}^{1}$,
}

1. Department of Anaesthesiology, Academic Medical Centre (AMC), University of Amsterdam, The Netherlands

2. Department of Internal Medicine, Academic Medical Centre (AMC), University of Amsterdam, The Netherlands

\section{Introduction}

Evidence regarding the optimal treatment of patients with diabetes mellitus in the perioperative period is scarce and variable. We surveyed diabetes protocols in Dutch hospitals hypothesizing that these would show considerable variability, reflecting the diverse literature on this topic.

\section{Methods}

We contacted all hospitals in the Netherlands by phone and (e-)mail to request their perioperative treatment protocol for patients with diabetes mellitus. In addition, we sent out a survey to gather information on preoperative preparation, diabetes medication management, glucose measurements and glucose targets, potassium co-administration and blood sugar control-strategies.

\section{Results}

Out of the 80 hospitals in the Netherlands, 72 responded to our request (response rate: $90 \%$ ). We received 55 protocols, 17 hospitals answered the questions in our survey.

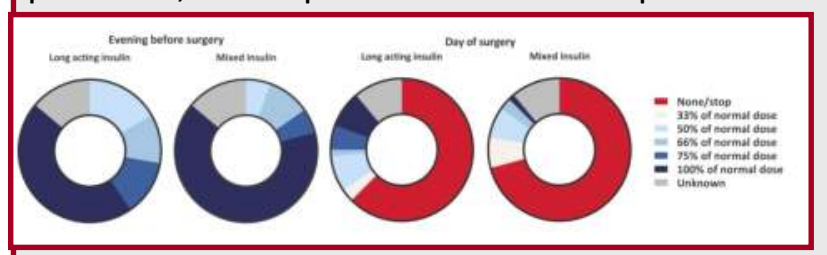

Upper left: In hospital preoperative policy on prescribed insulin on the day before surgery and the day of surgery for patients already taking insulin.

Upper right: The perioperative glucose targets for every responding hospital. Median upper glucose target was 10 $\mathrm{mmol} \mathrm{I}^{-1}$ (range 6-20), whereas the median lower target was $4 \mathrm{mmol} \mathrm{I}^{-1}$ (range 2-8).

Lower left: First action in protocol in case of hypoglycaemia.

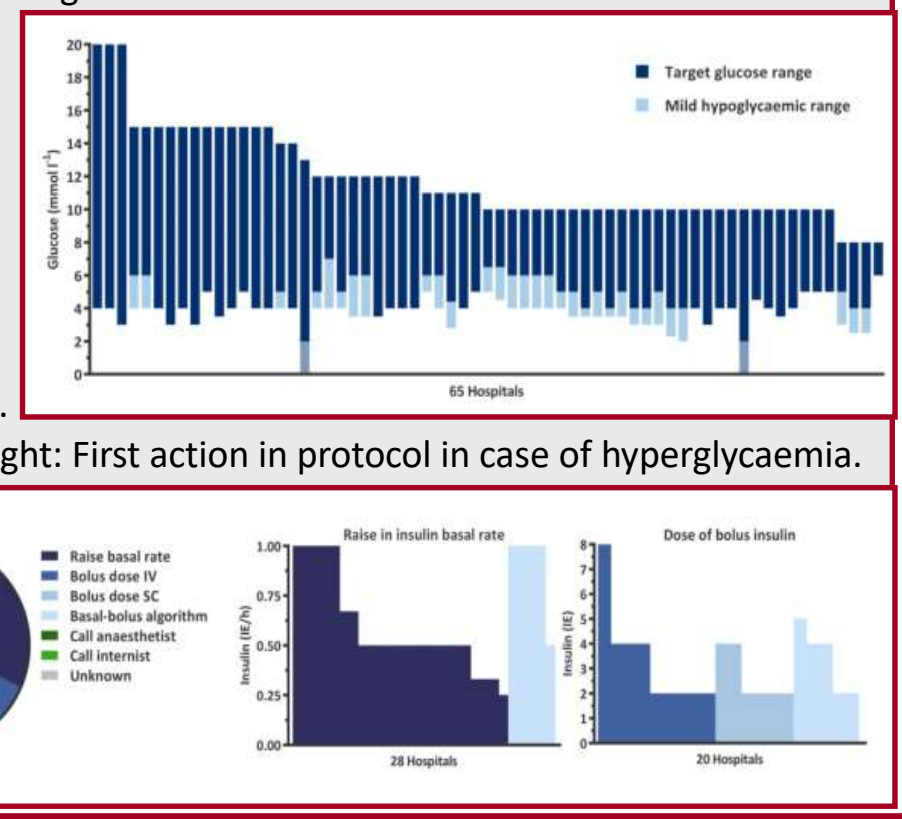

\section{Conclusion}

We found a large variability between hospital protocols for perioperative diabetes mellitus management. This reflects the variability of literature and paucity of evidence on perioperative diabetes management and stresses the need for clinical research on this topic to improve clinical guidelines. 